\title{
Narrativas sobre a inclusão de uma criança autista: desafios à prática docente
}

\author{
MARIANA HELENA SILVA DA LUZ* \\ CANDIDO ALBERTO GOMES ${ }^{* *}$ \\ ADRIANA LIRA*** \\ Universidade Católica de Braślia, Brasil
}

Recibido el 05-01-2016; primera evaluación el 17-05-2016; segunda evaluación el 31-05--2016; tercera evaluación el 22-10-2016; aceptado el 29-10-2016

\section{Resumo}

O autismo é tema amplamente explorado na literatura. Apesar disso, a inclusão escolar da criança autista ainda se constitui um desafio. Partindo deste pressuposto, o objetivo da pesquisa foi identificar quais os desafios da prática docente no acompanhamento de uma criança autista e em que condiçóes a sua inclusão ocorreu. A pesquisa qualitativa, de natureza descritiva e exploratória foi realizada nos meses de agosto a outubro de 2014 em uma instituição privada de Brasília. Em síntese, o estudo leva, por meio de entrevistas semiestruturadas e observação in loco, a concluir que a proposta de inclusão da escola, na qual parecem apostar os pais, é fragilizada pela falta de preparo dos profissionais, fato oriundo da precariedade da formaçáo inicial e continuada destes.

Palavras-chave: aprendizagem, educação infantil, educação inclusiva, autismo, prática docente.

\footnotetext{
* Pedagoga pela Universidade Católica de Brasília. Contacto: marianahelenaluz@hotmail.com * Professor titular do Programa de Mestrado e Doutorado em Educação da Universidade Católica de Brasília. Doutor em Educação pela Universidade da Califórnia, Los Angeles, EUA. Contacto: adrianaliraucb@gmail.com

${ }^{* * *}$ Mestre e doutoranda em Educação pela Universidade Católica de Brasília e professora. Contacto: candidoacg@gmail.com
} 


\section{Narratives on the Inclusion of Autistic Students: Challenges and Teaching} Practices

\section{Abstract}

Autism is a widely explored theme in the literature. Nevertheless, school inclusion among autistic children still constitutes a challenge. On this basis, the general goal of this research was to identify the challenges of teaching practices in the monitoring of an autistic student and in which conditions his inclusion occurs. The qualitative research, descriptive and exploratory in its nature, is characterized as a case study that was conducted in the months of August to October 2014 in a private institution of Brasilia. In summary, the study, by means of semi-structured interviews and on-site observations, concluded that the school»s inclusion proposal, in which parents seem to trust, is weakened by the lack of professional preparation, a fact derived by the precariousness of initial and continuous training of these professionals.

Keywords: learning, early childhood education, inclusive education, autism, teaching practice.

\section{Narrativas de la inclusión de un nińo autista: desafíos para la práctica docente}

\section{RESUMEN}

El autismo es un tema ampliamente explorado en la literatura. Sin embargo, la inclusión escolar de los niños autistas sigue constituyendo un desafío. Basándose en esta suposición, el objetivo general de esta investigación fue indentificar los desafíos de la práctica docente en el seguimiento de un niño autista y en qué condiciones se produce su inclusión. El carácter cualitativo, descriptivo y exploratorio, está caracterizado como un estudio de caso que se realizó en los meses de agosto a octubre de 2014 en una institución privada de Brasília. En resumen, el estudio, através de entrevistas semi-estructuradas y observaciones in situ llegó a la conclusión de que la propuesta de inclusión de la escuela, en la que apuestan los padres, está debilitada por la falta de preparación profesional, hecho derivado de la precariedad de la formación inicial y continua de los mismos.

Palabras clave: aprendizaje, educación infantil, educación inclusiva, autismo, práctica docente. 


\section{INTRODUÇÃo}

O conceito de Educação Inclusiva surgiu a partir de 1994 com a Declaração de Salamanca (Unesco, 1997). Com ela, ganha fortalecimento a ideia de que as pessoas com necessidades educativas especiais sejam incluídas de forma efetiva em escolas de ensino regular. Ela compreende a Educação Especial dentro da escola regular e transforma a escola em um espaço para todos. Favorece a diversidade na medida em que considera que todos os alunos podem ter necessidades especiais em algum momento de sua vida escolar. O objetivo da inclusão demonstra um avanço da civilização, defendendo que nenhuma criança deve ser separada das outras por apresentar algum tipo de deficiência ou transtorno. Deste modo, a Declaração de Salamanca ampliou o conceito de necessidades educacionais especiais, incluindo as crianças que não estejam conseguindo se beneficiar com a escola, seja por que motivo for (Menezes \& Santos, 2001).

Ao longo dos anos, a inclusão ganhou visibilidade entre os pesquisadores em diferentes contextos geralmente para averiguar se a sua proposta é de fato passível se colocar em prática e se a escola tem conseguido cumprir o seu papel de inclusão.

Passados os 20 anos de sua publicação, a Declaração de Salamanca ainda não se concretizou num direito exercido por todas as crianças. Garantir o direito à educação às crianças com necessidades especiais não requer apenas a integração destas junto às demais no ensino regular, conforme prevê a Declaração de Salamanca, que prevê que a escola inclusiva deve reconhecer e responder às diversas necessidades de seus alunos, acomodando tanto estilos como ritmos diferentes de aprendizagem e assegurando uma educação de qualidade a todos através de currículo apropriado, modificaçôes organizacionais, estratégias de ensino e uso de recursos. Porém, essa proposta não é possível ser executada sem uma formaçáo docente adequada para lidar com a criança que necessita de apoio diferenciado não apenas na rede pública de ensino, mas também na instituição privada.

Partindo deste pressuposto, o presente artigo tem objetivo narrar a partir do caso do menino Júnior, os desafios enfrentados pela professora e sua auxiliar pedagógica, buscando desta forma, identificar quais os desafios da prática docente para acompanhamento de uma criança autista e em que condiçóes a inclusão ocorre.

Neste intuito, foram abordados os seguintes aspectos, que nortearão o leitor para a compreensão dos dados de pesquisa: 1) A aprendizagem na educaçáo infantil; 2) A educação regular x especial: a educação inclusiva e 3) Transtorno do espectro do autismo (TEA): uma realidade educacional. Em seguida, 
passa-se à apresentação da pesquisa com os resultados e discussóes e, por fim, às consideraçóes finais. Espera-se, desta forma, que o presente estudo possa contribuir para a reflexão sobre os cursos de licenciatura para rever seu currículo e, ainda, para o trabalho de gestores escolares, reconhecendo que a proposta de uma educação inclusiva requer professores preparados.

\section{A APRENDiZagem NA EDUCAÇÁo INFANTIL}

A educação infantil, definida na Lei de Diretrizes e Bases da Educação Nacional - LDB (Brasil, 1996) era até então parte da educação básica, mas não da educação obrigatória. Contudo, a Lei no 12.796 de 4 de abril de 2013, torna obrigatória e gratuita a educação básica dos 4 (quatro) aos 17 (dezessete) anos de idade (Brasil, 2013). Com isso, as redes municipais e estaduais de ensino têm até 2016 para se adequar e acolher alunos desta faixa etária.

O Ministério da Educação (MEC) determinou que, a partir de janeiro de 1999, todas as creches do País deveriam estar credenciadas nos sistemas de ensino. Conforme a LDB, cabe aos sistemas municipais a responsabilidade maior por esses atendimentos. A Constituição da República diz que «A educação é direito de todos e dever do Estado» (Brasil, 2012). A Emenda Constitucional n. ${ }^{\circ}$ 14/96 alterou dispositivos relativos à educação e estabeleceu que a educação infantil é atribuição prioritária dos municípios.

A educaçáo infantil tem-se revelado primordial para uma aprendizagem efetiva nos anos seguintes. Ela socializa, desenvolve habilidades, melhora o desempenho escolar futuro, propiciando à criança resultados superiores ao chegar ao ensino fundamental. A educação infantil é o verdadeiro alicerce da aprendizagem, importante para as demais etapas do desenvolvimento das crianças.

$\mathrm{Na}$ fase dos dois aos cinco anos de idade, o lúdico exerce papel importante na aprendizagem das crianças, pois estudos comprovam que elas aprendem com mais facilidade e de forma mais prazerosa, conforme defendiam Piaget (1978) e Vygotsky (1987). Do contrário, é difícil conseguir a concentração das crianças que, nesta faixa etária, tendem a ser dispersas. Neste processo, o professor destaca-se como um mediador de conhecimentos e náo um transmissor como destacou o educador Paulo Freire (1996, p. 52) «ensinar náo é transferir conhecimentos, mas criar as possibilidades para a sua própria produção ou a sua construção».

Para Figueiredo, Micarello e Barbosa (2005), o debate sobre a Educação Infantil tem promovido discussóes no meio acadêmico. Tais discussôes dizem respeito às características, às competências e aos saberes necessários 
ou desejáveis aos professores que trabalham com crianças nessa faixa etária, exigindo deles habilidades e formação adequada.

A diversidade das situações educativas que emerge no contexto da Educação Infantil tem direcionado a necessidade de uma formaçáo que contemple as especificidades da educação nessa fase da vida. Sobre isto, Rocha (1999) assinala que o trabalho com a criança pequena implica uma multiplicidade de aspectos, saberes e experiências específicas que evidenciam a importância de se discutirem quais domínios devem ser contemplados na formação desses profissionais.

Partindo destes pressupostos, o aprendizado requer uma série de cuidados e planejamento que, organizado adequadamente, resulta em desenvolvimento mental e póe em movimento diversos processos de desenvolvimento que de outra forma, seriam impossíveis de acontecer» (Vygostsky, 1987, p. 101).

\section{A edUCAÇÃo REgUlar X ESPECIAL: A EDUCAÇÃo INCLUSIVA}

Desde a década de 1980, o ensino é dividido em regular e especial. E a partir de 1990, a educação inclusiva surge com o entendimento de que a escola é um lugar para todos. Daí a escola inclusiva ser tão almeja em leis, declaraçóes, documentos oficiais etc.

Desta forma, nos últimos anos, a inclusão, além de gerar polêmicas, por não se tratar de uma tarefa simples, passou a ser considerada para alguns, o maior desafio escolar em todo o mundo (Ainscow, 2009). A nosso ver, a inclusāo foi se constituindo ao longo das últimas décadas num paradigma na educação.

Mais precisamente, é na década de 1990 que a educação inclusiva ganha mais força (Figueira, 2011), com a premissa de fazer com que o ambiente escolar se torne mais envolvente e acolhedor, de modo a permitir o convívio de alunos sem ou com deficiência (visual, auditiva, motora, etc.), onde todos são tratados com igualdade. Nesta perspectiva, Scárdua (2008, p. 5) destaca que:

A diversidade enriquece uma sala de aula pelo simples motivo de se prender com o diferente. Para ela, quanto maior a diversidade na sala, não só com relação a várias deficiências, mas a diversidade cultural, de origem, de credo, de gênero, a física, faz a pessoa aprender mais, a conhecer mais o mundo, a perceber que há mais lá fora do que se possa imaginar [...] sendo possível, desta forma, sonhar com um mundo sem preconceitos e discriminaçôes.

De acordo com Ainscow (2009), a educação inclusiva supóe que o objetivo da inclusão educacional seja eliminar a exclusão social, que é consequência de atitudes e respostas à diversidade. Existe uma suposiçáo comum de que inclusão é principalmente acerca de educação de estudantes com deficiência, 
ou os classificados como portadores de necessidades educacionais especiais, nas escolas regulares. Contudo, verifica-se na literatura que existem vários questionamentos acerca da expressão deficiência, ganhando, pois, maior abrangência e esforço para a quebra da estigmatização. Por sua vez, Sampaio e Sampaio (2009) chamam a atenção para o problema da perda de precisão que acarreta na indefinição do alunado que efetivamente requer educação especial. Deste processo surge, ainda, segundo Sampaio e Sampaio (2009), uma nova reconceitualização para o termo deficiência, passando a ser usada a expressão necessidades educacionais especiais para evitar deste modo efeitos negativos de outras expressóes utilizadas no contexto educacional - deficientes, excepcionais, superdotados etc.

Por essas razóes, o termo «necessidades especiais» não deve ser tomado por sinônimo de deficiências, uma vez que as necessidades educacionais podem ser identificadas em diversas situaçôes representativas de dificuldades de aprendizagem oriundas das condiçóes individuais econômicas ou socioculturais dos alunos (Brasil, 1999).

No universo da inclusão, todas as pessoas têm acesso às oportunidades de ser e estar na sociedade, sendo, pois, a humanização do caminho. Para tanto, a escola ao lado da família exerce um papel importante na formação das crianças não apenas com deficiência, mas também para crianças sem deficiência, pela possibilidade da convivência com a diversidade e do estímulo à cidadania (Sampaio \& Sampaio, 2009). Portanto, ganha importância na educação inclusiva o papel mais formativo e ético da escola, na medida em que promove uma educação respeitosa e significativa para cada criança, favorecendo deste modo a cada uma a consciência de que todos sáo igualmente beneficiários de direitos e deveres e incentiva o debate permanente sobre causas coletivas (Sampaio \&Sampaio, 2009). No entanto, subentende-se que a educação inclusiva requer uma modificação por parte da escola para que o modelo inclusivo ocorra de forma efetiva. Assim, apenas receber as crianças deficientes na escola ou realizar adaptaçóes físicas não são açóes suficientes para receber os alunos com deficiência de aprendizagem, mas é essencial haver mudanças nos processos pedagógicos que invistam nas relaçóes estabelecidas entre as crianças, permitindo-lhes a convivência, aliás, interação importante para a troca de conhecimentos segundo proposta do sócio-interacionismo de Vygotsky (1987).

\section{Transtorno do Espectro do Autismo (TEA): uma realidade EDUCACIONAL}

Considerando que a literatura sobre o autismo é bastante ampla, aqui no presente artigo, priorizamos a apresentação de informaçóes elementares para o 
entendimento do tema. O autismo, assim como a educação inclusiva, reúne um número considerável de publicaçôes, contudo, o número de trabalhos envolvendo crianças autistas ainda carece de maiores aprofundamentos. $\mathrm{O}$ acervo da Universidade Católica de Brasília, por exemplo, tem em seu repositório três dissertaçôes de Mestrado da própria instituição: Duar (2002), Braga (2009) e Brandão (2009), que destacam esta necessidade.

O autismo infantil é uma síndrome, uma condição crônica com início sempre na infância, em geral até o terceiro ano de vida (Schawartzman, 1994). Esta síndrome é caracterizada pela dificuldade de a criança conseguir estabelecer relaçôes afetivas, daí a sua dificuldade de socialização (Gonçalves, 2010). Além disso, a criança com autismo apresenta dificuldades na linguagem tanto verbal como não verbal. Schawartzman (1994, p. 7) confirma estas mesmas informaçōes:

O autismo infantil (AI) é uma síndrome definida por alterações presentes desde idades muito precoces e que se caracteriza, sempre, pela presença de desvios nas relações interpessoais, linguagem/comunicação, jogos e comportamento, hiperatividade e movimentos repetitivos.

A literatura aponta Kanner como o percussor para o diagnóstico autista em 1943 (Schawartzman, 1994; Mello, 2007). Por essa razão, o autismo é também conhecido como "Síndrome de Kanner». O seu estudo contribuir para identificar retardos mentais e distúrbios do comportamento, formando uma proposta de descrição clínica muito utilizada no diagnóstico de crianças autistas (Schawartzman, 1994). Além dos determinantes biológicos, o AI pode apresentar outros sinais decorrentes da disfunção neurológica de que são portadoras, tais como deficiência mental (em graus variáveis), distúrbios de atenção-concentração, crises convulsivas e prejuízos motores e/ ou perceptuais, mudança brusca de humor, repetiçóes do que os adultos falam entre outras características. Desta forma, o autismo é considerado um transtorno global do desenvolvimento (Boettger, Lourenço \& Capellini, 2013).

As causas do autismo não são tão bem definidas. Porém, desde 1943 já ocorria uma tentativa de caracterizaçáo desta síndrome que, para Kanner, consiste numa síndrome congênita. A incidência é maior em meninos, sendo uma proporção de seis meninos para cada menina (Schawartzman, 1994). No que se refere à sua pessoa física, o autista apresenta características normais e tem uma memória notável em algumas áreas. Foi o que comprovou a pesquisa (Gonçalves, 2010). Nessa direção a necessidade de o professor conhecer o estudante para trabalhar as suas habilidades a serviço de sua aprendizagem. No entanto, não se exige que o professor se torne um perito na detecção de 
características autistas em uma criança, até porque o seu diagnóstico não é tarefa tão simples e exige cuidados. No entanto, a escola como um todo conta com o apoio de materiais ricos e disponíveis gratuitamente para identificaçáo de uma criança autista, inclusive com atividades específicas para trabalhar com elas (Monte \& Santos, 2004).

Para Mello (2007), o processo de aprendizagem das crianças autistas se dá pela associação e tem dificuldades de generalização espontânea do conhecimento adquirido, exigindo, portanto, um trabalho mais específico. Ainda sobre o aprendizado da criança autista, Mello (2007) destaca que para ela o campo da visáo é importante, uma vez que aprende mais vendo do que ouvindo. Assim, a demonstraçáo é importante para que ela execute a atividade proposta, além de exigir paciência do professor para que se repitam inúmeras vezes até que ela vá aos poucos adquirindo sua autonomia.

No processo de inclusão, é preciso cuidado com a rejeição da criança que que pode por sito ter uma crise de comportamento. Assim, a relação professor-aluno destaca-se como uma base de controle, segurança e confiança do aluno de forma que ele controle paulatinamente os seus impulsos (Mello, 2007).

$\mathrm{Na}$ educação inclusiva, a atividade física e recreativa, além da hora do lanche, sáo momentos oportunos de desenvolver no estudante autista a sua capacidade relacional do aluno com o professor, dele com outros colegas, desenvolver expressóes corporais e faciais, capacidades motoras que contribuirão para autoestima e desempenho independente (Tomé, 2007).

\section{Metodologia}

Trata-se de uma pesquisa qualitativa de natureza descritiva e exploratória. A estratégia para tanto foi o estudo de caso, realizado nos meses de agosto a outubro de 2014 em uma instituiçáo privada de Brasília situada em uma comunidade de nível socioeconômico médio baixo.

A pesquisa qualitativa valoriza a busca do significado e da interpretação, visando gerar conhecimentos aplicados a um contexto particular e real (Minayo, 1994), lidando com muitas variáveis e fontes de evidências ao mesmo tempo (Yin, 2005).

Para geração dos dados, foi realizada uma entrevista semiestruturada com a auxiliar pedagógica e a professora regente e ainda foram realizadas observaçóes in loco. Para Duarte (2004), a entrevista semiestruturada permite ao pesquisador uma organizaçáo flexível e ampliação dos questionamentos à medida que as informaçóes vão sendo fornecidas pelo entrevistado. Contudo, este foi um desafio para estes pesquisadores, já que a professora náo permitiu a 
gravação. Patton (1987) considera ser a entrevista de suma importância para se preservar o conteúdo original e aumentar a precisão dos dados, visto que ela seria posteriormente transcrita.

Por sua vez, a observação assistemática, também conhecida por ocasional, simples, não estruturada, é aquela que «se realiza sem planejamento e sem controle anteriormente elaborados, como decorrência de fenómenos que surgem de imprevisto» (Rudio, 1999, p. 41), enriquecendo assim o caso estudado.

\section{Caracterizaçáo da escola}

A escola tem 50 anos de fundação e é composta por 14 salas de educação infantil, sendo três salas de maternal, sete salas da pré-escola e quatro de ensino fundamental.

O seu atendimento se dá nos turnos matutino e vespertino. No turno matutino, existem duas crianças autistas na pré-escola e, no turno vespertino, uma criança no Ensino Fundamental.

No que se refere à estrutura física, pode-se considerar que a escola é um espaço bem estruturado e agradável, com espaços de leitura, biblioteca e parques, porém isso por si só não garante um trabalho profícuo se não usado pela professora.

Apesar da presença dessas crianças, a escola não tinha, até o momento da pesquisa, nenhum projeto de inclusão das mesmas, mas as recebeu.

\section{Caracterizaçáo dos participantes}

\section{a. A auxiliar pedagógica}

É formada em Pedagogia, tem Pós - Graduação em Gestão Escolar. Atua na área da Educação há 18 anos e está na instituição pesquisada como Auxiliar Pedagógica há dois anos.

\section{b. A professora da turma $A$}

A partir do preenchimento de um questionário com questôes abertas e fechadas, foi possível traçar o perfil da professora. Esta tinha mais de 40 anos de idade, possuía graduação em Pedagogia e especialização, mas afirmou não ter uma formação específica na área de Educação Especial e sobre Inclusão. A mesma declarou possuir entre seis a dez anos de atuação na educação infantil e é professora da escola pesquisada há 17 anos. No momento, a professora exercia uma carga horária de 22 horas semanais. 


\section{c. O menino Júnior (nome fictício)}

O Júnior tem quatro anos, estuda na pré-escola no período matutino e está matriculado na escola pesquisada desde o início do ano letivo. $\mathrm{O}$ aluno frequentou uma creche antes de efetivar a matrícula na escola atual. Ele Pertence a uma família de nível socioeconômico médio alto. O Júnior é filho único. É difícil de lidar com o seu humor. Ele apresenta, segundo a psicóloga que o acompanha, características associadas a de um autista, mas não possui um laudo que comprove isso, pois os seus pais náo aceitam o diagnóstico de autismo. Entretanto, os pais e a escola assim o consideram por possuir as seguintes características: falta de concentração, mudanças de humor, repetição de palavras que as pessoas acabam de falar, como por exemplo, «Obrigada, Júnior», «Bom dia, turma» etc. Além disso, verifica-se a ausência de interação social e de linguagem verbal. Tem interesse por objetos como sapato, tesoura etc., no entanto, eles não são inseridos no processo de aprendizagem do Júnior.

O menino Júnior frequenta a psicóloga e, a cada sessão, a clínica entra em contato com a orientadora educacional para lhe passar um relatório que possa subsidiar a escola em seu trabalho. No entanto, nem a professora nem a auxiliar pedagógica têm acesso a este relatório.

\section{d. A auxiliar pedagógica da turma A}

A auxiliar pedagógica, que atua no acompanhamento do menino Júnior, receberá o nome fictício de Juliana. É concluinte do curso de Pedagogia. Tinha no momento da pesquisa 22 anos de idade e foi contratada pela escola pesquisada em 2011. Está acompanhando o menino Júnior há 6 meses. Sua função é auxiliar as professoras, os alunos, a coordenação, seja para substituir professor, seja para atender a pais de alunos ou atender a alunos com problemas comportamentais, para fazer a oração inicial ou circular pelos corredores e responder a necessidades urgentes na escola.

\section{Resultados}

\section{A observaçáo in loco}

O período de observação se deu ao longo do mês de setembro, três vezes por semana. A turma A conta com o total de 22 estudantes. Dentre elas, apenas o Júnior é uma criança com transtorno global do desenvolvimento.

Foi possível verificar que o menino Júnior chega frequentemente atrasado à escola, deixando, por isso, de participar da acolhida das crianças no horário 
da entrada (7h30). Com mais de uma hora de atraso, o Júnior perde a socialização na roda de conversa que a professora faz todos os dias, fragilizando, assim, a proposta de integração do Júnior às demais crianças.

Apesar de o Júnior estar na escola desde o início de 2014, tem resistência a ficar na sala de aula. Durante as observaçóes, ele mostrou-se frequentemente inquieto, sempre irritado, faz gestos obscenos como "dar a língua», além de agredir os colegas, que sentem medo dele e apresentam comportamentos preconceituosos, geralmente despercebidos pela professora. Por essas razóes, seus pais são frequentemente chamados à escola. Contudo, acompanhando uma conversa dos pais com a professora, foi possível perceber que os pais responsabilizam a professora pela falta de pulso firme para com o seu filho. Segundo a professora, os pais não aceitam o diagnóstico de autista para o filho, mesmo após o retorno do psicólogo que o acompanha, fragilizando, assim o trabalho que poderia ser feito na inclusão do Júnior. Apesar disso, os pais são bem presentes na educação do Júnior e nas reunióes docentes. Neste momento, os pais costumam mostrar descontentamento com o trabalho da professora, que, para eles não é competente para desenvolver o seu trabalho. Talvez, este nível de cobrança tenha levado a professora ao estresse. Ela se disse desmotivada pela presença do Júnior em sala de aula. Quando perguntada sobre o que fazia para conseguir reverter este quadro, a professora sempre alegava que o número de 22 estudantes ser elevado para uma só turma. Talvez, a falta de uma clara concepçáo do papel da auxiliar pedagógica pela professora devesse ser melhor esclarecida, para que, juntas, realizassem um trabalho em conjunto objetivando a inclusão dos alunos em geral.

Neste processo de acompanhamento, verificou-se que o Júnior gosta muito de assistir a desenhos animados, exibidos na escola. É o que se pode perceber na interação entre Juliana, auxiliar pedagógica, e ele. No entanto, isto não era utilizado como elemento capaz de contribuir para a sua aprendizagem. $\mathrm{Na}$ verdade, a professora náo se mostrava motivada em conhecer o Júnior, para depois trabalhar com ele.

Ao final da aula, geralmente o Júnior já está muito irritado, chora muito, bate nos colegas, chama pelos pais e fica totalmente disperso das atividades. Assim, não conseguindo envolver o Júnior nas atividades, ele tem o seu desempenho comprometido. Apesar do comportamento irritado do Júnior, verifica-se que ele tende a se relacionar um pouco melhor com as meninas, gostando inclusive dos pertences delas.

Em virtude deste quadro, no início do ano letivo, a escola solicitou aos pais a contratação de uma auxiliar pedagógica para acompanhamento exclusivo do menino Júnior. Assim, segundo a coordenadora pedagógica e a professora, 
os pais atenderam a solicitação da escola. Contudo, a auxiliar ficou pouco tempo na escola e deixou o acompanhamento, porque ela não iria mais disponibilizar tempo para acompanhar o Júnior em suas sessóes com a psicóloga. Neste período, o aluno melhorou ainda que pouco, conseguindo o pelo menos um pouco mais de concentração nas tarefas. Apesar disso, os pais não mais quiseram contratar outra auxiliar pedagógica. Desde então ele tem ficado somente com a professora regente e, às vezes, com a Juliana.

A auxiliar pedagógica, a Juliana, afirmou ter começado auxiliar a professora no acompanhamento do Júnior no início de julho de 2014, porém foi contratada pela escola e não pelos pais do Júnior. Assim, ela não é uma exclusividade dele. Sendo poucas as auxiliares pedagógicas da escola (apenas três auxiliares), a Juliana não pode ficar à disposição da professora do Júnior e dele todos os dias, pois, quando há falta de professores na aula, por exemplo, as auxiliares assumem a turma ou auxiliam em outras necessidades da escola.

No período de acompanhamento enquanto auxiliar pedagógica, a Juliana pode verificar que a relação da professora como o menino Júnior não é satisfatória, pois ela acaba se irritando com as limitaçóes e comportamentos dele. No entanto, não se verificou neste período uma tentativa de mudança por parte da professora, que constantemente expressou a preocupação de ter um auxiliar para «tomar conta» dele. Ou seja, por muitas vezes a professora queixou-se de náo conseguir desenvolver o trabalho com a turma e acompanhar o Júnior.

Apesar disso, o Júnior pergunta por ela o tempo todo quando a aula é com professor de outra área, como, por exemplo, Educação Física, Religiáo e Música. Assim, a auxiliar pedagógica demonstra-se preocupada com a situação e, por isso, levanta as seguintes indagações: será que as crianças se dão conta da forma como a professora trata o Júnior? Será que ele mesmo sente isso?

Apesar da dificuldade de concentração e do aprendizado lento, o Júnior é inteligente e entende os comandos, mesmo que ele recuse a fazer as tarefas. Por exemplo, ele reconhece o próprio nome, gosta de mostrar para as professoras que sabe contar a idade que tem, pede para verem que ele está limpo, que tomou banho, que cuidou da higiene (palavras dele). Esses aspectos demonstram que, se houvesse acompanhamento diário de uma auxiliar pedagógica, além do trabalho da professora, o Júnior poderia paulatinamente ter o seu desempenho melhorado.

Em suma, a auxiliar pedagógica também não possuía conhecimentos para atuar junto a uma criança autista. No entanto, ela afirmou que, depois do contato com o Júnior, passou a ler sobre o Transtorno do Espectro do Autismo (TEA) para melhor assisti-lo, pois considera que neste período de sua experiência profissional conseguiu envolver-se emocionalmente com ele, já que com 
ela (a Juliana), o Júnior demonstra mais segurança e afeto na sala de aula. Este fato sugere que, se a professora tivesse este mesmo comportamento para com o Júnior, ele náo sentisse tanto a falta da Juliana. Contudo, para evitar um vínculo maior, a escola não permite que a auxiliar pedagógica o acompanhe todos os dias.

A auxiliar pedagógica declarou que, no início, não gostou muito da ideia de ter que ficar em sala junto à professora só para «cuidar» do aluno autista, pois nada conhecia sobre o referido transtorno. Mas, durante o processo, viu que náo era necessário "cuidar» e sim ajudar, incentivar e abrir portas para a criança. De acordo com a experiência da auxiliar pedagógica, o Júnior sabe que é diferente e que seus colegas se afastam dele porque também assim o consideram.

Para a auxiliar pedagógica, que acompanha o Júnior mais de perto, ele, ao seu ritmo, melhorou significativamente, pois, descobrindo que suas habilidades eram desenhar, recortar, mexer com cola, investiu nisso para trabalhar com ele. Além disso, foi possível percebê-lo mais sociável nas observaçóes em sala de aula e durante outras atividades recreativas, pois demonstrou já entender que não pode bater nos colegas.

Portanto, verificou-se que é preciso observar que o desenvolvimento de uma criança como o Júnior se dará de uma forma progressiva. Para tanto, querer fazer a diferença enquanto docente é um elemento fundamental neste processo de inclusão do Júnior e das demais crianças.

\section{A entrevista com a professora}

Durante o processo da entrevista com a professora, foi possível sentir que ela não estava preparada para desenvolver um trabalho de inclusão nem para atuar com crianças com necessidades educativas especiais. Inicialmente, a professora preencheu um breve questionário com questóes acerca de seu perfil e mediante um instrumento de entrevista semiestruturada coletaram-se algumas informaçôes anotando o que a entrevistada relatava, visto que a mesma não permitiu gravação, talvez por não querer comprometer o seu emprego por se tratar de uma instituição privada de ensino.

$\mathrm{Na}$ verdade, a brevidade de suas respostas sugeriu desconhecimento acerca da educaçáo inclusiva e também não permitiu aprofundar outros aspectos que previram estes pesquisadores quando optou pelo instrumento de entrevista semiestruturada.

Para a professora, a educação inclusiva consiste na «capacidade de entender e reconhecer o outro e, assim, ter o privilégio de conviver e compartilhar com pessoas diferentes de nós». Esta palavra privilégio intrigou um pouco 
estes pesquisadores. No entanto, a referida professora não deu abertura para maiores aprofundamentos. Aguardou-se outra oportunidade, mas não surgiu como nós esperávamos.

Apesar de pouco aprofundamento, a professora demonstra conhecer um pouco acerca da lei que estabelece a educação inclusiva, apontando a LDB e a Constituição Federal:

A nossa Constituição garante desde 1988 o acesso à educação para todos , sendo que estudantes com necessidades especiais devem receber atendimento especializado, preferencialmente na escola. A LDB para a educação básica busca acima de tudo, a valorizaçáo desses alunos em seus paradigmas e dificuldades (Entrevista com a professora).

No que se refere à sua formação, a professora afirmou: «A escola já promoveu uma especialização sobre neurociência e Educação Inclusiva e eu fiz». No entanto, na parte objetiva do questionário, ela escreveu que não possuía formaçáo específica para atuar com crianças especiais.

Quanto à formação específica sobre o autismo, ela evidenciou despreparo:

Não sou especialista em atuar com crianças autistas. Este ano, tenho o Júnior, mas ele ainda náo tem o laudo fechado, mesmo tendo todas as características de autista. Sempre busco refletir sobre a minha prática pedagógica e o trabalho com uma criança autista é uma experiência estimuladora e o professor que tem esse privilégio fica mais seguro para argumentar a favor da inclusão.

Quando solicitado que a professora falasse de sua experiência com o menino Júnior, ela respondeu: «Meu papel é compreendê-lo em suas possibilidades, acreditar nele e ajudá-lo em suas conquistas e progresso no dia a dia».

No que se refere ao subsídio que recebe para o trabalho com o Júnior, a professora afirmou:

É importante o acompanhamento dos pais e da psicóloga. A presença da auxiliar pedagógica é muito importante, pois a família não acha que seja necessário, acham que o Júnior conseguirá sozinho desenvolver-se sem que tenha alguém para ajudá-lo a realizar as tarefas de sala, pois sozinha eu não consigo acompanhá-lo por causa do restante da turma. Os pais ajudam o Júnior nas tarefas que enviamos para casa.

Quanto ao desempenho do menino Júnior, a professora afirmou que «acompanhar o rendimento dele se trata de um processo difícil, já que ele não tem concentração, mas a avaliação de seu aprendizado se dá através de observaçóes contínuas para averiguar o crescimento, além do desenvolvimento de atividades desenvolvidas em sala de aula e ainda a interação. Tudo isso, vai para o relatório». 
Porém, em nenhum momento da aula, verificou-se a atenção da professora para com o Júnior e muito menos o acompanhamento de suas tarefas. Por hora, buscamos ter acesso ao referido relatório para verificar se o mesmo registrava de fato o que acontecia, mas o acesso ao mesmo não foi possível.

Em suma, percebemos que a professora não tinha domínio do tema da inclusão. Durante a entrevista, se perdeu em suas palavras, pedindo que esperasse antes de fazermos qualquer anotação.

Para nós pesquisadores, a afetividade e o respeito da Juliana, auxiliar pedagógica, pelo menino Júnior contribuíram para as mudanças percebidas no Júnior. Por exemplo, a prática de olhar dentro dos seus olhos, estar perto, envolvê-lo, abaixar-se para falar com ele e estar «à altura dele», são pequenos gestos que, a nosso ver, fizeram a diferença.

Apesar destes resultados, a escola pensa que o acompanhamento diário ao Júnior pode acomodar os respectivos pais do Júnior.

Além de outros apontamentos já feitos neste artigo, verificamos que não apenas o menino Júnior tem sido prejudicado, mas também as demais crianças que, não sendo trabalhadas para conviver com o diferente, acabam por desenvolver preconceitos, como se percebeu em sala.

Além disso, questiona-se a atuaçáo da professora, cujas aulas são monótonas não apenas para uma criança autista, mas para os estudantes em geral. A professora parece se esquecer de que está a atuar na educação infantil, onde o lúdico exerce um papel fundamental na aprendizagem das crianças. Assim sendo, a professora demonstrou lacunas na formação inicial e uma urgente necessidade de uma formação continuada, já que atua demonstrando uma obrigação e não um prazer.

Para nós, o desenvolvimento do Júnior requer tempo e investimento. Assim, é fato que sozinho, como parecem apostar os pais e a professora, dificilmente avançará na mesma proporção que os seus colegas.

No entanto, o que pudemos verificar no depoimento da professora e sua auxiliar pedagógica, é que a temática da inclusão não é discutida na formação continuada dos professores, que se realizam semanalmente na escola. Em entrevista, a professora afirmou que a gestora da escola sempre menciona querer abordar a temática em um futuro próximo: «A partir do próximo ano, pretendo trazer palestras e trazer artigos para serem trabalhados nas formaçóes continuadas que são realizadas na escola». Assim, parece que o desafio de um trabalho profícuo de inclusão das crianças autistas parece «sobrar», pois as professoras contempladas com a presença destes alunos, por sua vez, não possuem formação específica para o acompanhamento destas crianças. Deste modo, parece que a escola, para se eximir de sua responsabilidade, transferindo 
seu dever para o professor, que também conta com pais e, que, por sua vez, esperam por um trabalho de excelência da escola.

Diante desta realidade, verificou-se que, tanto a auxiliar pedagógica quanto a professora, se encontravam um pouco esquivas para colaborar com este estudo, talvez por se tratar de emprego particular, dando informaçóes muito breves acerca de questionamentos, que, inclusive, não foram gravados, uma vez que lhes foram respeitadas as condições das participantes para a não gravação de suas falas tal qual propóem Hernández Sampieri, Fernández Collado e Baptista Pilar (2006).

\section{CONCLUSÓES}

O objetivo deste trabalho foi identificar quais os desafios da prática docente para acompanhamento de uma criança autista e em que condiçóes a inclusão ocorre. O estudo evidenciou uma série de fragilidades no caso da «inclusão» do menino Júnior.

Verificou-se, apesar de a inclusão de uma criança autista não ser problema novo, que ainda constitui desafio para a instituição escolar, mesmo privada. Em relação a ela, existe uma falsa ideia das pessoas de que, por ser particular, está melhor preparada para subsidiar a criança autista.

Outro aspecto preocupante se trata da falta de um diagnóstico, como no caso do Júnior, que dificulta o processo de inclusão que se espera da escola. $\mathrm{O}$ Júnior precisa de um diagnóstico que, inclusive, servirá como um ponto de partida para se trabalhar com os pais da criança no sentido não só de aceitá-lo, mas preparar-se para melhor subsidiá-lo.

Foi notório que a proposta de inclusão, na realidade pesquisada, ainda não saiu do papel. Além disso, não basta reconhecer que os alunos são "diferentes», mas apontar com segurança a natureza dessas diferenças. Neste sentido, o professor, sendo o mediador das aprendizagens, tem um papel fundamental no desenvolvimento desta criança e, para conseguir alcançar um bom resultado, precisa estar preparado.

A educação inclusiva requer investimento na formação dos professores e ainda o envolvimento da sociedade, visto que o que se percebe acerca da inclusão é um total despreparo da sociedade em geral e das instâncias educacionais em particular (Sampaio \& Sampaio, 2009).

No entanto, esta formação docente não trata de torná-lo profundo conhecedor "do transtorno", mas potencializar para a ação técnica de referência aquele que ensina, uma vez que o conhecimento especializado pode servir 
como um complemento valioso, mas o conhecimento do professor é elementar para sua ação (Baptista, 2003).

A presença da auxiliar pedagógica é controversa, porém, o que se percebeu é que a presença da Juliana foi importante para a professora, mas mais ainda para o Júnior. No entanto, verificamos que a professora e sua auxiliar precisavam ter clareza de seus papéis neste processo.

Verificou-se a partir da literatura que a mudança para a acolhida de crianças intelectualmente especiais requer preparo maior da escola como um todo não apenas no que se refere à sua infraestrutura, mas também um preparo maior dos profissionais que avaliem a sua atenção junto às crianças para conhecê-las e melhor assisti-las (Figueiredo, 2000; Sampaio \& Sampaio, 2009).

Fica para nós um questionamento acerca do número elevado de alunos na sala de aula, em que o menino Júnior fica por conta da auxiliar pedagógica, a Juliana, que precisa dar tempo para a professora regente desenvolver o seu trabalho com os demais alunos. $\mathrm{O}(\mathrm{a})$ auxiliar pedagógico(a) pode ser de grande valia para o trabalho da professora junto à criança, contudo, ambos professor(a) e auxiliar pedagógico precisam da formação e consciência do seu papel no processo acompanhamento dela. Não foi o que aconteceu no caso do menino Júnior em que a presença da auxiliar pedagógica funciona apenas como uma «válvula de escape», para ter com quem deixar o Júnior, fragilizando assim o trabalho de inclusão, que deixa de ocorrer, uma vez que ele é isolado do processo que ocorre durante a aula com os demais colegas. Além disso, é importante uma relação próxima entre professor e auxiliar pedagógica para que a professora tenha um retorno do desempenho da criança. Pareceu que a professora não tinha a concepção clara de que a função da auxiliar é, como o próprio nome sugere, auxiliar o Júnior em sala de aula e náo assumir sozinha a responsabilidade pela criança, pois assim não faria sentido inserir a criança em um espaço de sala de aula maior, junto a outras crianças. Espera-se que o convívio com outras crianças influencie o aprendizado da criança autista, assim como acontece na relação entre as crianças num processo de interação.

O cansaço sugerido pela professora regente e o seu desânimo após a presença do menino Júnior em sala devem ser avaliados pela escola, pois, se não houver um suporte ao professor, pode ocorrer o adoecimento e ao sentimento de impotência deste quando se sente obrigada a trabalhar com a criança.

Outro aspecto fundamental se refere à persistência do professor. No caso do Júnior, a professora não demonstrou persistência para com as limitaçóes do aluno, fragilizando, portanto, o processo de inclusão que se supóe a escolar estava realizando. 
O estudo corrobora a literatura no que se refere ao atendimento da criança autista, que não só requer a sua recepção na escola, mas toda uma consciência e preparo que o Transtorno do Espectro do Autismo (TEA) requer dos adultos para com as crianças especiais. No estudo em pauta, verificou-se que há fragilidades não apenas no que se refere à formação e prática docente, mas no despreparo e náo aceitaçáo dos pais e também na escola como um todo, que «transfere» a responsabilidade para a professora e não subsidia também a sua formação, não favorecem o processo de inclusão.

Em suma, pode-se concluir que a inclusão da criança autista é um dever de todos que, ao contrário, podem estar sendo cúmplices da sua exclusão presente e futura da sociedade.

\section{REFERÊNCIAS BIBLIOGRÁFICAS}

Ainscow, Mel (2009). Tornar a educação inclusiva: como essa tarefa deve ser conceituada? In Osmar Fávero, Windyz Ferreira, Timothy Ireland e Débora Barreiros (orgs.), Tornar a educação inclusiva (pp. 11-24). Brasília: Unesco. Recuperado em 17 de outubro de 2014 de http://unesdoc.unesco.org/ images/0018/001846/184683por.pdf

Baptista, Cláudio Roberto (2003). Sobre as diferenças e desvantagens: fala-se de qual educaçáo especial? In C. Maraschin, L. B. L Freitas e D. C. Carvalho (orgs.), Psicologia da educação: multiversos sentidos, olhares e experiências (pp. 45-55). Porto Alegre: UFRGS.

Boettger, Andréa Rizzo dos Santos, Lourenço, Ana Carla \& Capellini, Vera Lucia Messias Fialho (2013). O professor da educaçáo especial e o processo de ensino-aprendizagem dos alunos com autismo. Revista Educação Especial, Santa Maria, 26(46), 385-400, maio/ago. Recuperado em 23 de outubro de 2014 de http://www.ufsm.br/revistaeducacaoespecial

Braga, I. S. (2009). «Teorizando as práticas de atendimento à pessoa com autismo na rede de escolas públicas do Distrito Federal». Dissertação (Mestrado em Psicologia). Universidade Católica de Brasília, Brasília, 2009. Recuperado em 24 out. 2014 de http://www.bdtd.ucb.br/tede/tde_busca/arquivo. php?codArquivo $=1061$

Brandão, Lúcia de Carvalho (2009). «Interação social em diferentes contextos escolares: estudo de caso de uma criança com autismo». Dissertação (Mestrado em Psicologia) - Universidade Católica de Brasília. Recuperado em 25 out. 2014 de http://www.bdtd.ucb.br/tede/tde_busca/arquivo. php?codArquivo= 1161

Brasil (1996). Lei 9394, de 23 de dezembro de 1996. Estabelece as Diretrizes e Bases da Educação Nacional. Brasília: MEC. 
Brasil (1999). Parâmetros curriculares nacionais. Adaptaçôes curriculares. Estratégias para educação de alunos como necessidades educacionais especiais. Brasília: MEC.

Brasil (2012). Constituição da República Federativa do Brasil. 35a. ed. Brasília: Câmara dos Deputados.

Brasil (2013). Lei 12.796 de agosto de 2013. Brasília: MEC. Recuperado em 12 de novembro de 2014 de http://www.planalto.gov.br/ccivil_03/_ato20112014/2013/lei/l12796.htm

Duar, Aline Altoé (2002). Caracteristicas, desenvolvimento e repertório comportamental na utilização do computador por duas crianças portadoras de transtorno autista. Dissertação (Mestrado em Educação) - Universidade Católica de Brasília.

Duarte, Rosália (2004). Entrevistas em pesquisas qualitativas. Educar em Revista, 24, 213-225. Curitiba. Recuperado em 03 de setembro de 2014 de http:// www.unisc.br/portal/upload/com_arquivo/entrevistas_em_pesquisa_qualitativas.pdf. https://doi.org/10.1590/0104-4060.357

Figueira, Emílio (2011). O que é educação inclusiva. São Paulo: Editora Brasiliense.

Figueiredo, F., Micarello, H. \& Barbosa, S. N. (2005). Autonomia de professores da Educação Infantil: «a coisa vira, e o professor se vira». Kramer, S. Profissionais da educação infantil: gestão e formação (pp. 156-170). São Paulo: Ática.

Figueiredo, Rita Vieira (2000). Políticas organizativas e curriculares, educação inclusiva e formação de professores. Rio de Janeiro: DP\&A.

Freire, Paulo (1996). Pedagogia da autonomia: saberes necessários à prática educativa. São Paulo: Paz e Terra.

Gonçalves, Mariana (2010). Compreendendo o autismo a partir de diferentes olhares. Monografia de Conclusão do Curso de Pedagogia. São Paulo: Faculdade Cenecista de Capivari - FACECAP.

Hernández Sampieri, Roberto, Fernández Collado, Carlos Fernandez \& Baptista Pilar, Lucio (2006). Metodologia da pesquisa. 3. ed. São Paulo: McGraw-Hill.

Mello, Ana Maria S. Ros de (2007). Autismo: guia prático. 7a ed. São Paulo/ Brasilia: AMA/Corde. Recuperado em 22 de outubro de 2014 de http:// www.autismo.org.br/site/images/Downloads/7guia\%20pratico.pdf

Menezes, Ebenezer Takuno de \& Santos, Thais Helena dos (2001). Verbete Declaração de Salamanca. Dicionário Interativo da Educação Brasileira Educabrasil. São Paulo: Midiamix. Recuperado em 28 de dezembro de 2015 de http://www.educabrasil.com.br/declaracao-de-salamanca/

Minayo, Maria Cecília de Souza (1994). Pesquisa social: teoria, método criatividade. Rio de Janeiro: Vozes. 
Monte, Francisca Furtado do \& Santos, Idê Borges dos (coords.) (2004). Saberes e práticas da inclusão, dificuldades acentuadas de aprendizagem: autismo. Brasília: MEC, SEESP.

Patton, Michael Quinn (1987). How to use qualitative methods in evaluation. Califórnia: Sage.

Piaget, Jean (1978). A formação do símbolo na criança: imitação, jogo e sonho. Rio de Janeiro: Zanar.

Rocha, E. A. C. (1999). «A pesquisa em educação infantil no Brasil: trajetória recente e perspectivas de consolidação de uma pedagogia da Educação Infantil». Tese (Doutorado em Educação) - Universidade Estadual de Campinas.

Rúdio, Franz Victor (1999). Introdução ao projeto de pesquisa científica. 24a. ed. Petrópolis: Vozes.

Sampaio, Cristiane T. \& Sampaio, Sônia Maria R. (2009). Educação inclusiva: o professor mediando para a vida. Salvador: EDUFBA. Recuperado em novembro de 2014 de http://static.scielo.org/scielobooks/3hs/pdf/sampaio-9788523209155.pdf. https://doi.org/10.7476/9788523209155

Scárdua, Valéria Mota (2008). Revista FACEVV, 1, 85-90. Espírito Santo. Recuperado em 20 de setembro de 2014 de http://www.facevv.edu.br/ Revista/01/A\%20INCLUS\%C3\%83O\%20E\%20O\%20ENSINO\%20 REGULAR.pdf

Schawartzman, José Salomão (1994). Autismo infantil. Brasília: Corde.

Tomé, Maycon Cleber (2007). Educação física como auxiliar no desenvolvimento cognitivo e corporal de autistas. Movimento \& Percep̧̧ão, 8(11), 231-248, jul./dez. São Paulo. Recuperado em 23 de outubro de 2014 de http:// ferramentas.unipinhal.edu.br/ojs/movimentoepercepcao/viewarticle. php?id=158

Unesco (1997). Declaração de Salamanca e linha de ação sobre necessidades educativas especiais. Brasília: Corde.

Vygotsky, Lev Semenovitch (1987). A formação social da mente. São Paulo: Fontes. Yin, R. (2005) Estudo de caso: planejamento e métodos. $4^{\mathrm{a}}$ ed. Porto Alegre: Bookman. 